\title{
Elemental interdiffusion in W-Ta composites developed for fusion applications
}

\author{
R. Mateus*, M. Dias**, V. Livramento***, D. Nunes*, P.A. Carvalho*****, K. Hanada***** and \\ J.B. Correia*,*** \\ *Associação Euratom/IST, Instituto de Plasmas e Fusão Nuclear, Instituto Superior Técnico, \\ Universidade Técnica de Lisboa, 1049-001 Lisboa, Portugal \\ **ITN/IST, Instituto Tecnológico e Nuclear, Instituto Superior Técnico, Universidade Técnica de Lisboa, \\ 2686-953 Sacavém, Portugal \\ ***Laboratório Nacional de Energia e Geologia, Estrada do Paço do Lumiar, 1649-038 Lisboa, Portugal \\ ****ICEMS, Instituto Superior Técnico, Universidade de Lisboa, 1049-001 Lisboa, Portugal \\ *****National Institute of Advanced Industrial Science and Technology (AIST), 1-2-1 Namiki, Tsukuba, \\ Ibaraki 305-8564, Japan
}

Tungsten (W) was select for an extensive use in nuclear fusion devices due to its low neutron activation, high melting point and sputtering threshold [1] as well as low hydrogen inventory [2]. Nevertheless, W is brittle at low and moderate temperatures, which results in abnormal thermal stress, component fracture and extra erosion under reactor operation due to inherent thermal cycling events. An attractive way to solve these problems involves the addition of other refractory metals in the $\mathrm{W}$ matrix and tantalum $\mathrm{Ta}$ ) is a natural candidate. It has a high ductility, toughness and radiation resistance relative to those of $\mathrm{W}$ [1] and transmutes to $\mathrm{W}$ by high-energy neutron irradiation. Recently, IST proposed the production of W-Ta composite by mechanical synthesis [3].

The composite should reveal the individual properties of the pristine phases as long as the interdiffusion between the components is significantly avoided during the consolidation/sintering route of the final material. Sintering operations at temperatures higher than $1300^{\circ} \mathrm{C}$ lead to significant improvements in the final densification and thermal conductivity of the composites, which is crucial for fusion applications [1]. However, W and Ta interdiffusion can be relevant above $1300^{\circ} \mathrm{C}$, mainly due to diffusion of $\mathrm{W}$ into $\mathrm{Ta}$ [4], and the aim of the present work is to control the mechanism.

$\mathrm{W}-\mathrm{Ta}_{\mathrm{f}}$ composites presenting 10 and 20 at.\% of Ta where produced by alloying $\mathrm{W}$ powders and Ta fibres with a planetary ball milling route (MA) and by consolidating the mixture with spark plasma sintering (SPS) in the 1300$1600^{\circ} \mathrm{C}$ temperature range. The final densifications remain fairly constant in both composites after sintering at different temperatures $\left(83\right.$ to $87 \%$ ) and the elemental interdiffusion remained low at $1300^{\circ} \mathrm{C}$. Nevertheless, the diffusivity of $\mathrm{W}$ in $\mathrm{Ta}$ became significant at $1600^{\circ} \mathrm{C}$, leading to the formation of a solid solution zone with a stoichiometry close to $\mathrm{W}_{16} \mathrm{Ta}_{84}$. The mechanism was followed by scanning electron and energy-dispersive $\mathrm{X}$-ray spectroscopies (SEM/EDS; Figures 1 and 2, Table 1). Fabrication routes yielding high densifications and low interdiffusion are currently under investigation.

The work has been supported by the Contract of Association between Euratom and IST and by the Fund. Ciência e a Tecnologia contracts PTDC/CTM/100163/2008, Pest-OE/SADG/LA0010/2011 and PEST-OE/CTM-UI0084/2011.

References

1. Rieth M. et al., J. Nucl. Mater., 417:463-467, 2011.

2. Wright G.M. et al., Nuclear Fusion, 50:055004, 2010.

3. Livramento V. et al., Proc. of the $1^{\text {st }}$ Intern. Conf. on Materials for Energy, vol. A: 268-270, 2010.

4. Ott R.T. et al., J. Mater. Res., 23:133-139, 2008. 

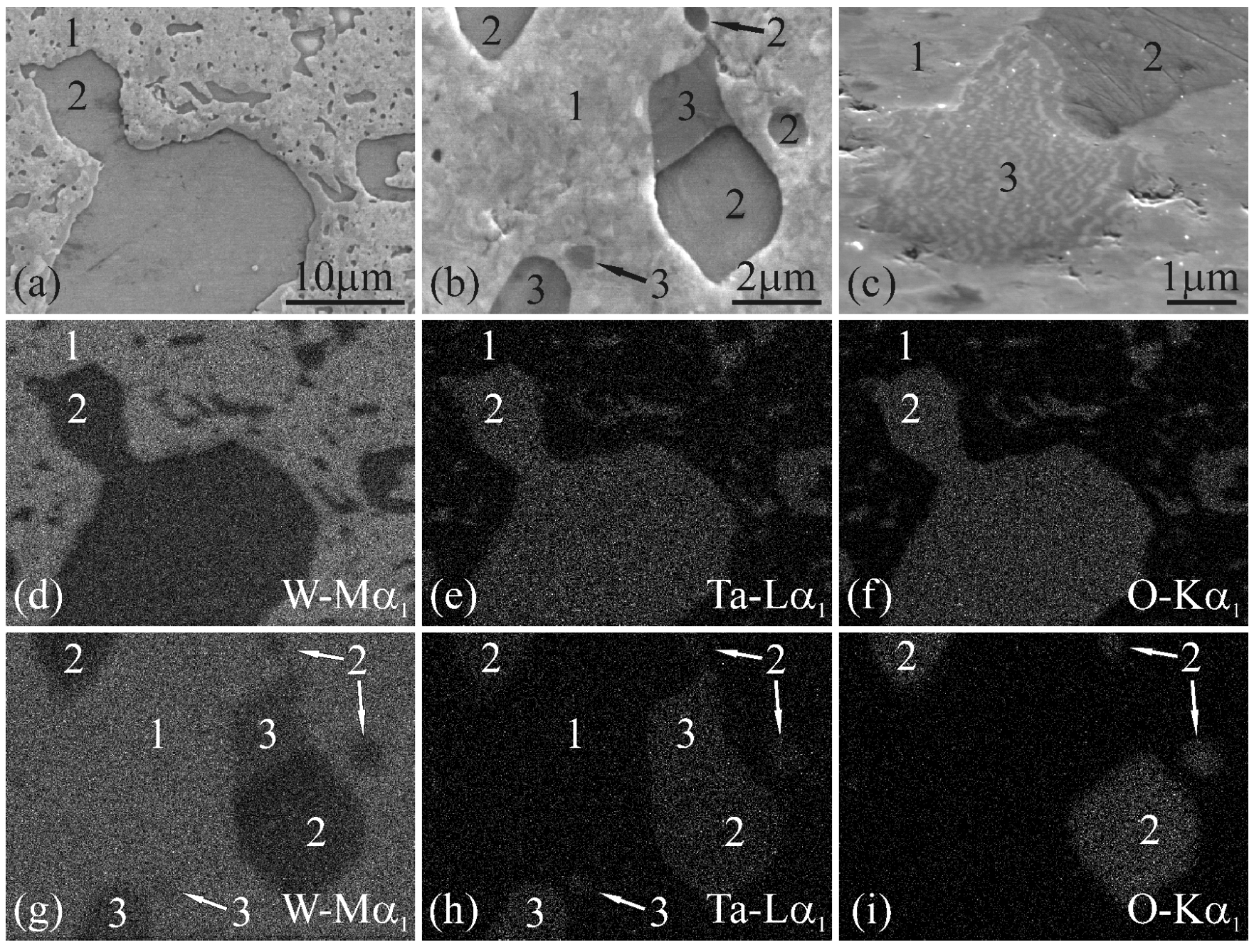

Figure 1. SEM images of $\mathrm{W}-\mathrm{Ta}_{\mathrm{f}}$ composites sintered at 1300 (a) and $1600^{\circ} \mathrm{C}$ (b) showing the $\mathrm{W}$ and $\mathrm{Ta}$ phases and a WTa solid solution in zones 1, 2 and 3, respectively; lamellar growth in a WTa solution (c); EDS distribution maps for $\mathrm{W}(\mathrm{d}), \mathrm{Ta}(\mathrm{e})$ and $\mathrm{O}(\mathrm{f})$ in figure 1.a; corresponding maps in figure 1.b $(\mathrm{g}, \mathrm{h}, \mathrm{i})$.

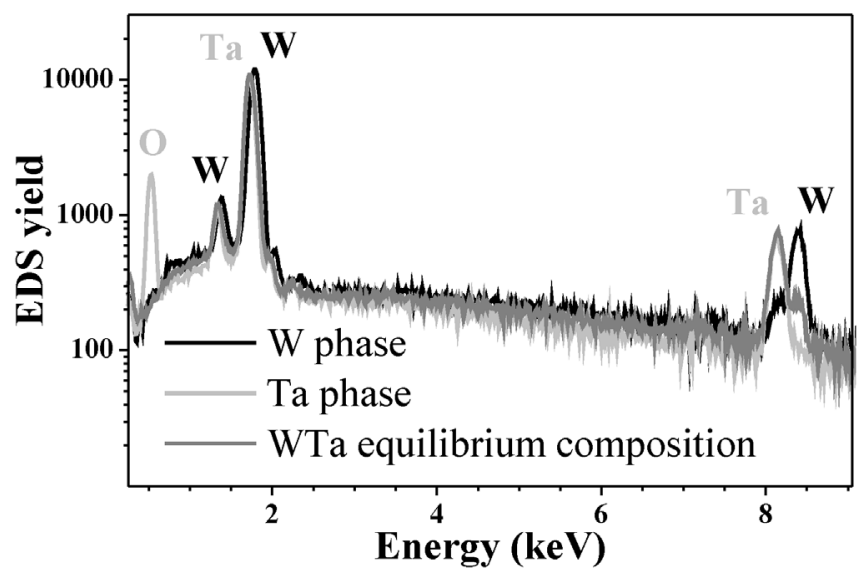

Figure 2. Representative EDS spectra of zones 1, 2 and 3 in the $\mathrm{W}-\mathrm{Ta}_{\mathrm{f}}$ composite sintered at $1600^{\circ} \mathrm{C}$.

Table 1. Main composition in zones 1, 2 and 3 in the $\mathrm{W}-\mathrm{Ta}_{\mathrm{f}}$ composite sintered at $1600^{\circ} \mathrm{C}$.

\begin{tabular}{lccc}
\hline Zone & \multicolumn{3}{c}{ Element (at.\%) } \\
\cline { 2 - 4 } & $\mathrm{W}$ & $\mathrm{Ta}$ & $\mathrm{O}$ \\
\hline Zone 1 & 90.5 & 9.5 & - \\
Zone 2 & 1.2 & 25.5 & 73.5 \\
Zone 3 & 16.0 & 84.0 & - \\
\hline
\end{tabular}

